\title{
HVMANITAS
}

\section{O modelo iconográfico da Minerva de Collippo e a sua importância histórica}

\author{
Autor(es): $\quad$ Correia, Virgílio Hipólito
}

Publicado por: Imprensa da Universidade de Coimbra

URL persistente:

URl:http://hdl.handle.net/10316.2/35107

DOI:

DOI:http://dx.doi.org/10.14195/2183-1718_66_16

Accessed : $\quad$ 26-Apr-2023 06:48:36

A navegação consulta e descarregamento dos títulos inseridos nas Bibliotecas Digitais UC Digitalis, UC Pombalina e UC Impactum, pressupõem a aceitação plena e sem reservas dos Termos e Condições de Uso destas Bibliotecas Digitais, disponíveis em https://digitalis.uc.pt/pt-pt/termos.

Conforme exposto nos referidos Termos e Condições de Uso, o descarregamento de títulos de acesso restrito requer uma licença válida de autorização devendo o utilizador aceder ao(s) documento(s) a partir de um endereço de IP da instituição detentora da supramencionada licença.

Ao utilizador é apenas permitido o descarregamento para uso pessoal, pelo que o emprego do(s) título(s) descarregado(s) para outro fim, designadamente comercial, carece de autorização do respetivo autor ou editor da obra.

Na medida em que todas as obras da UC Digitalis se encontram protegidas pelo Código do Direito de Autor e Direitos Conexos e demais legislação aplicável, toda a cópia, parcial ou total, deste documento, nos casos em que é legalmente admitida, deverá conter ou fazer-se acompanhar por este aviso. 
humanitas

Vol. LXVI

2014

IMPRENSA DA UNIVERSIDADE DE COIMBRA

COIMBRA UNIVERSITY PRESS 


\title{
O modelo iconográfico da Minerva de Collippo e a SUA IMPORTÂNCIA HISTÓRICA.
}

\author{
The ICONOGRAPHIC MODEL OF THE MineRVA FROM \\ COLLIPPO AND ITS HISTORIC IMPORTANCE
}

\begin{abstract}
Virgílio Hipólito Correia
Museu Monográfico de Conimbriga, Faculdade de Letras da Universidade do Porto, Centro de Estudos de Arqueologia Artes e Ciências do Património diretor@mmconimbriga.dgpc.pt
\end{abstract}

\section{Resumo}

É estudada a cabeça de estátua representando Minerva proveniente da antiga Collippo (S. Sebastião do Freixo, Batalha) e identificado o seu modelo iconográfico, numa peça similar do templo de Apolo Sosiano em Roma; são identificadas outras peças do mesmo modelo.

Propõe-se que esta peça representa um vestígio de uma intervenção no fórum da antiga cidade provavelmente atribuível ao período claudio-neroniano e é discutida a sua relação com fenómenos congéneres na capital da província da Lusitânia.

Palavras-chave: Collippo, Minerva, S. Sebastião do Freixo

\begin{abstract}
A statue head representing Minerva from the ancient Collippo (S. Sebastião do Freixo, Batalha) is studied and its iconographic model is identified in a similar piece from the temple of Apollo Sosianus in Rome; other pieces of the same model are identified.

It is proposed that this piece represents a remain of an intervention in the forum of the ancient town probably dating from the Claudio-neronian period and its relation to similar processes occurring in the capital of the province of Lusitania is discussed.
\end{abstract}

Keywords: Collippo, Minerva, S. Sebastião do Freixo 


\section{A peça}

A cabeça de Minerva proveniente da antiga Collippo (S. Sebastião do Freixo, Batalha $)^{1}$ foi estudada por V. de Souza $^{2}$ e por L. J. R. Gonçalves ${ }^{3}$ coincidindo ambos no facto de não ser possível apontar um modelo iconográfico para esta representação de Minerva armada, mas com o armamento realizado em bronze aplicado ao corpo da estátua.

Conservada numa colecção particular, a peça foi cedida temporariamente para a inauguração em 2011 do Museu da Comunidade Concelhia da Batalha, contexto em que o Laboratório de Conservação e Restauro do Museu Monográfico de Conimbriga procedeu a uma operação de limpeza da cabeça, que permitiu uma análise mais pormenorizada; esta leva a considerar menos pertinentes algumas considerações sobre a fraca qualidade da escultura ${ }^{4}$, como aliás já tinha sido sugerido 5 .

A cabeça foi realizada em mármore branco, provavelmente lusitano (pedreiras de Borba-Estremoz?), e mede actualmente $39 \mathrm{~cm}$ de altura. Ligeiramente virada para a direita, a face apresenta-se bem modelada, com maçãs do rosto cheias e lábios bem delineados; as pálpebras são finas e bem traçadas.

Toda a calote craneana foi deixada por trabalhar, tendo o topo da cabeça sido inclusivamente rebaixado de forma não anatómica. Localizam-se aí três orifícios que se destinariam a fixar o elmo metálico. Na zona do occipital foi traçada uma faixa de cerca de $2 \mathrm{~cm}$ de largo que remataria o para-nuca desse elmo.

No frontal e parietais representou-se o cabelo, ondulado, caindo a ambos lados da cara a partir de uma risca central.

A estátua poderá ter sido representada numa proporção próxima de 1,5 vezes o natural.

A peça sofreu extensos danos do seu lado esquerdo, que destruíram completamente o nariz e martelaram gravemente o olho esquerdo, os lábios e o queixo. A exposição da peça à intempérie nos últimos anos levou a uma fortíssima colonização por líquenes, que em nada a beneficiou, mas a qualidade da peça, como dito, é saliente.

1 Bernardes 2007: 120-121; id. 2010: 111-112.

2 Souza 1990: 47, nº 133.

3 Gonçalves 2007: 246-247.

4 Souza 1986: 132.

5 Nogales e Gonçalves 2008, loc. cit. 
O segundo dos mencionados autores segue o primeiro em propor uma datação claudiana para a peça, baseada numa aproximação com a cabeça de Agripina Maior do criptopórtico do fórum de Aeminium ${ }^{6}$.

Todavia, a alegada inexistência de modelo iconográfico merece mais exame, o que aqui se tentará fazer, parecendo possível encontrar tal modelo e avançar um pouco no que a sua utilização numa cidade provincial da Lusitânia significa, do ponto de vista histórico.

\section{0 modelo iconográfico}

A representação de Minerva como Atena armada (a Pallas Athena) era tradicional na Península Itálica, mas estatuária sua com o armamento realizado em bronze aplicado sobre o corpo marmóreo, terá sido conhecida em Roma, de visu, desde a remodelação do templo de Apolo in Circo por C. Sosius em 33 a.C. ${ }^{7}$, como E. La Rocca demonstrou ${ }^{8}$. Nessa data, foi colocada no frontão do templo uma tal estátua, proveniente muito provavelmente do templo de Apolo Dafnéforo de Eretria, fazendo desse templo romano uma "mostra" de escultura grega de muito relevo".

Esta representação de Minerva/Atena faz parte de um vasto conjunto de representações acrolíticas ${ }^{10}$, com originais gregos espalhados por vários museus do mundo, representados emblematicamente pela chamada "Athena Vogüê", do Louvre (Inv. MA 3109), mas distingue-se delas pela existência de uma verdadeira estátua, decorada com acessórios em bronze, mais do que uma simples composição de vários elementos em diversos materiais, como os acrólitos típicos. É, por outro lado, interessante verificar como em cidades como Cirene a popularidade deste tipo de representação conduziu à sua multiplicação e às dificuldades de encontrar uma opinião firmada consensual quanto à sua produção e datação ${ }^{11}$.

Como certo, pode tomar-se que a presença do conjunto estatuário grego original no templo de Apolo (doravante, Sosiano) em Roma, se constituiu em elemento de referência artística de relevo, independentemente do percurso

6 cf. Nogales e Gonçalves 2004: 306; id. 2008: 682-684.

7 Lugli 1946: 536-542; Blake 1947: 158.

8 La Rocca 1996: 13-33.

9 La Rocca 1985; Zanker 1990: 66-70; cf. também Hartswick 2004, 102-103.

10 Como foi notado em Nogales e Gonçalves 2008: loc. cit.

11 Paribeni 1959: 24, no 29, e outros; Huskinson 1975: 166-167, nº 122-124; Häger-Weigel 1997: 96-98. 
político individual de C. Sosius - que provinha do campo de António - e da sua relação com Octaviano. O regime augustano incorporou a intervenção como sua ${ }^{12}$, beneficiando da dedicatória original por um $\mathrm{Cn}$. Iulius ${ }^{13}$; o templo de Apolo Sosiano ficou dessa forma fazendo parte dos programas urbanísticos da época do segundo triunvirato que marcaram a urbs.

Buscando os processos de transmissão deste modelo até à Lusitânia, segundo a proposta metodológica de P. León ${ }^{14}$, somos conduzidos, em primeiro lugar, ao Norte de Itália, onde se conhecem duas cabeças deste modelo: uma em Veneza, da antiga colecção de Giovanni Mocenigo (Museo Archeologico Nazionale di Venezia, Inv. 264B), outra de Brescia, actualmente no Museo di Santa Giulia dessa cidade (Inv. MR 2). Mas também aqui se encontram disparidades sensíveis nas classificações feitas e nas datações atribuídas, a propósito da peça veneziana ${ }^{15}$.

Em qualquer caso, e como pelo menos a peça da antiga Brixia é certamente romana, encontra-se aqui mais um exemplo significativo dos processos de transmissão que correm paralelamente no Norte de Itália e na Península Ibérica, que foram observados já noutros elementos ${ }^{16}$.

\section{Os modelos artísticos adoptados na Lusitânia}

A análise da cabeça de Minerva de Collippo obriga a considerar estar-se perante um caso - reputadamente raro - em que um modelo artístico com origem em Roma surge numa (pequena) cidade sem uma evidente presença na capital provincial, onde se supõem ter estado sedeadas as oficinas que alimentaram a edilícia pública ${ }^{17}$. Certamente que muitas considerações sobre os processos pós-deposicionais ocorridos quer nas cidades provinciais quer nas capitais poderão explicar tal raridade como apenas aparente, mas a situação merece alguma reflexão.

Existe uma extensa bibliografia sobre os aspectos mais notáveis da adopção na capital da Lusitânia dos modelos artísticos do Fórum de Augusto, transpostos para o fórum da colónia ${ }^{18}$.

12 Zanker loc. cit.; Gurval 1995: 116-119 esp. n. 73.

13 Lugli, loc. cit..

14 León 2011: 24-32.

15 Traversari 1973: 38; Beschi 1986: 131-143.

16 Casari 2011: 93-97.

17 Nogales e Gonçalves 2004: 293-300.

18 Nogales e Álvarez 2005; Nogales 2007a, ambos c/ bib. anterior. 
Existe todavia um problema de interpretação do programa iconográfico, particularmente no que diz respeito à cronologia.

A posição tradicional atribui esse programa a datas claudio-neronianas ${ }^{19}$. Opiniões posteriores propuseram uma datação mais baixa, em época flaviana, baseadas na ligação escultura/arquitectura e num ponto de referência, o dos relevos flavianos da Cancelleria, de forma que, todavia, se tem de considerar como insuficientemente probatória ${ }^{20}$.

O problema desta última posição reside na circularidade do argumento, pois os escavadores reconhecem que a datação do monumento só é possível através da decoração arquitectónica ${ }^{21}$, já que não se identificaram contextos datáveis de deposição primária ligados à construção que constituam termini ad quem. Portanto, a melhor datação arqueológica possível resume-se a uma flecha larga correspondente grosso modo à segunda metade do séc. I d.C. ${ }^{22}$. Desta forma, é na análise comparativa da escultura e na cronologia de um monumento de Roma que a datação se baseia; questionada - como ocorre $^{23}$ - a cronologia da referência cai o raciocínio e, mesmo que não se cure de um juízo aprofundado sobre a polémica, que como todas as da história de arte tende a extravasar da análise objectiva para apreciações meramente estéticas, quando não emocionais, é manifestamente fundação insegura para edifícios de monta.

Ora, há o elemento incontornável da presença de Agripina Minor a contextualizar $^{24}$ : parece de todo em todo improvável que no período flaviano se tenham erigido monumentos a este membro da linhagem julio-claudiana; sendo certo que, quando eles existiam, os Flávios não os removeram. O elemento essencial é o da existência, no fórum de Mérida de um programa iconográfico de época claudio-neroniana. Tal programa é uma manifestação de um movimento mais ambicioso, que atinge outros monumentos públicos da cidade, como o teatro ${ }^{25}$ ou o fórum provincial ${ }^{26}$, num movimento de largo fôlego que não pode deixar de ter influenciado os notáveis de outras

19 Álvarez e Nogales 2003: 271-277; Trillmich 2005, passim, c/ bib. anterior.

20 Peña 2009: 614-617.

21 Ayerbe et al. 2009a: 766.

22 Ayerbe et al. 2009b: 816-824.

23 Referências em Peña loc. cit.

24 Trillmich 2007: 436-440.

25 Trillmich 2005: 277-282; Nogales 2007b: 112-115.

26 Röring e Trillmich 2010. 
cidades da província na hora de fazer as escolhas para os monumentos das suas próprias responsabilidades locais.

Este elemento é importante para a compreensão da presença da Minerva inspirada num original grego em Collippo, na medida em que esta demonstra que outros modelos artísticos que compuseram a grande renovação de Roma ao longo do reinado de Augusto viajaram também até às províncias e sendo que, se o grande movimento de marmorização da decoração dos monumentos da capital provincial se centra na época claudiana, tal fenómeno deve também ocorrer nas restantes cidades.

\section{A escultura de Collippo}

Collippo já foi reconhecida como cidade particularmente beneficiada na época julio-claudiana, sendo aí muito importante a presença de Tiberii Claudii $^{27}$. A estátua de Minerva pode ter feito parte de uma intervenção arquitectónica e/ou urbanística associada ${ }^{28}$.

Dada a relevância da intervenção propriamente agripiniana na importação dos modelos artísticos e ideológicos da época do segundo triunvirato para a Lusitânia, seria talvez a esse momento específico que a Minerva, inspirada no produto dos saques de C. Sosius, deveria ser associada; a dilacção temporal entre modelo e produto não deve ser motivo de estranheza: um evidente conservadorismo faz, em certa medida, parte do próprio programa ideológico a ser implementado em datas claudio-neronianas sob a inspiração da imperatriz e é também visível noutras expressões da arquitectura pública ${ }^{29}$.

Como J. Alarcão já sugeriu ${ }^{30}$, pode haver um movimento de larga duração entre o desenho dos programas urbanísticos e a sua efectiva implementação, estendendo-se ao longo de todo o período de Augusto a Cláudio-Nero, o que justificaria a presença, mesmo nas datas mais tardias, de referências a Agripa $^{31}$, a que todavia não deve ter sido estranho um intencional aproveitamento da sua própria genealogia por parte de Agripina.

$\mathrm{Na}$ complexa interpenetração dos fenómenos de patrocínio imperial, iniciativa provincial e encomenda local que conduziriam finalmente à construção

27 Alarcão 1990: 26; Bernardes 2007: 117-118.

28 Alarcão 1993: 195-196.

29 Mierse 1999: 174-203.

30 Alarcão 2004: 269.

31 Cf. Pensabene 2004: 184. 
de monumentos públicos, à sua decoração escultórica e à instalação de programas iconográficos ${ }^{32}$ a investigação fica naturalmente dividida entre o movimento de aprofundamento do conhecimento individual das peças ou dos edifícios e da sua datação mais precisa e a necessidade de compreender na sua globalidade os "programas", tal como foram pensados pelos seus fautores e efectivamente instalados (o que pode nem sempre ter coincidido).

A sugestão forte de que a Minerva de Collippo foi estátua de culto de um templo decorado em época claudio-neroniana segundo um modelo urbico da época do segundo triunvirato é, neste sentido, muito importante per si, mas só ganha o relevo adequado quando colocado num contexto mais geral.

Olhando para a evolução dos centros forenses de Mérida, parece claro, da evidência actualmente disponível, que a ênfase no culto imperial se faz sentir em dois momentos principais: um primeiro sob Tibério e o segundo momento, agripiniano. Por contraste, na parte ocidental da província, onde todavia se deve descontar o facto de a evidência ser de modo geral menos bem datada, parece ser possível apreciar uma concentração mais decisiva no segundo momento ${ }^{33}$. Não seria de estranhar, em qualquer caso, que o panorama geral da província se sucedesse no tempo, e não acompanhasse estritamente, a evolução na capital provincial.

Mas a situação original talvez tenha tido outras nuances. Sabe-se que, no início do reinado de Calígula, o seu legado C. Ummidius Durmius Quadratus promoveu um juramento de fidelidade ao imperador, de que sobreviveu a cópia dos Aricienses ${ }^{34}$. E que este juramento, e com ele a projecção da imagem da casa imperial, estava destinada a ter uma concretização palpável na paisagem urbana das cidades da Lusitânia, é comprovado pelo facto de três dos "Augustos" póstumos conhecidos na província (Conimbriga, Sellium e Myrtillis) serem remodelações de retratos de Caio ${ }^{35}$.

Há aqui, porventura, uma outra diferenciação entre os processos em curso na capital e nas outras cidades provinciais: naquela a damnatio memoriae é rigorosamente implementada; nestas consente-se numa menos dolorosa (até economicamente) "remodelação" do imperador vilipendiado no antepassado da família. Mas em contexto local e contemporâneo o carácter utilitário da solução não pode ter deixado de ser sentido.

32 Nogales 2011: 664-666.

33 Sobre Conimbriga, em último lugar Correia 2013: 357-359.

34 CIL II 172=ILS 190; Encarnação 1984: 703-706.

35 Nogales e Gonçalves 2004: 326.

Humanitas 66 (2014) 309-322 


\section{Sugestões}

O nosso conhecimento das realidades antigas será sempre, quase por definição, parcelar e fragmentário.

A Minerva de Collippo é um bom exemplo desse facto, sendo porventura mais numerosas e importantes as questões que deixa em aberto, do que as respostas que oferece.

Em primeiro lugar, está a forma como a estátua de Athena do templo de Apolo Dafnéforo de Eretria, reinstalada no frontão do templo de Apolo in Circo (logo dito Sosiano) por C. Sosius, se constitui em modelo artístico para a difusão de uma mensagem imperial nas províncias.

Terão, porventura, jogado papel importante neste processo alguns elementos de natureza muito diversa; entre eles poderia estar o efectivo prestígio gozado por um original grego colocado em posição eminente num edifício público, ancestralmente ligado à família Julia; noutra linha de influência pode ter estado alguma particularidade em concreto do culto de Minerva na antiga Collippo, que não estamos em condições de imaginar, mas que pode ter tido outra manifestação na ocorrência, sui generis, de uma inscrição dedicada à deusa in memoriam de uma defunta ${ }^{36}$.

A segunda grande questão é a da data, ou melhor das datas, atribuíveis à estátua e à sua instalação. A primeira resposta será a de que a imagem de Minerva teria feito parte de um programa instalado quando Agripina, a Jovem, desempenha um papel crucial na afirmação da família imperial, nas suas múltiplas relações: descendente de Augusto; também de Agripa (o que seria relevante na Lusitânia); irmã de Caio (este ponto talvez menos eloquentemente afirmado); mulher de Cláudio e de facto tutora de Nero. Mas a concentração programática dos programas iconográficos imperiais neste momento, que é muito aparente em Mérida e, por exemplo, em Conimbriga, talvez mascare um movimento de mais longa duração, de origem tiberiana, perturbado talvez por alguns aspectos mais extremos do principado de Calígula e que a casa de Cláudio, através da imperatriz, tenta recuperar para maior coesão do império. Que este fenómeno se identifique com mais clareza em Augusta Emerita e na província de que ela é cabeça, é natural considerando o papel especial de Agripa como deductor da colónia - nenhum outro membro da família imperial detinha melhor genealogia que Agripina para manipular neste sentido a sua imagem. 
O que convoca uma terceira e (por agora) última questão: é este problema explicável, única e simplesmente, pelo desejo latente dos notáveis locais (em Mérida, como em Collippo ou em Conimbriga) de emular a urbs? Ou existe ainda em meados do séc. I d.C. uma consciência difusa, na sede do poder imperial, da necessidade de trazer a si e aí manter estas franjas do império? (E a consciência dos perigos incorridos com os excessos de Calígula era mais séria que o escândalo postiço de que se faz eco Suetónio?).

Estas questões dirigem-se a uma tentativa de refinar o nosso entendimento da interpenetração, nas respostas concretas encontradas em cada cidade romana, entre os desejos locais, as capacidades de resposta encontradas em cada província e as condições mais gerais em que a política imperial se move. O modelo iconográfico da Minerva de Collippo, a Athena do templo de Apolo Dafnéforo de Eretria que C. Sosius saqueou para benefício da urbs e que, instalada no frontão do templo de Apolo Sosiano, ficou a fazer parte do grande programa octaviano de embelezamento de Roma, é uma interessante e importante pista de indagação desta problemática.

\section{Agradecimentos}

Pela colaboração na obtenção de informações e fotos das peças referidas, são devidos e gostosamente dados agradecimentos a Pedro Sales (Museu Monográfico de Conimbriga); Ana Moderno (Museu da Comunidade Concelhia da Batalha); British Museum Image Services; Michela Sediari (Museo Archeologico Nazionale di Venezia) e Francesca Morandini (Museo di Santa Giulia, Brescia).

João Pedro Bernardes, José da Silva Ruivo e um revisor anónimo leram uma primeira versão deste artigo, tendo feito importantes sugestões e comentários; a responsabilidade pelos erros subsistentes é do autor.

\section{Ilustrações}

1 - Minerva de Collippo, na sua localização no jardim da residência a cuja colecção particular pertence (fotos Pedro Sales () MMC/DGPC).

2 - Minerva de Collippo (foto (C) Museu da Comunidade Concelhia da Batalha).

3 - Atena do templo de Apolo Sosiano (nos Museus do Vaticano. Foto Barbara Malter, seg. La Rocca 1996, p. 15, fig. 2).

4 - Acrólito de Cirene (Foto $\odot$ Trustees of the British Museum). 
5 - Cabeça colossal de Atena ou Minerva do Museo Archeologico Nazionale di Venezia (foto (C) Soprintendenza Speciale per il Patrimonio e per il Polo Museale di Venezia).

6 - Minerva de Brixia (foto Piera Tabaglio (C) Museo di Santa Giulia, Brescia).

\section{Referências}

Alarcão, J. (1990) "Identificação das cidades da Lusitânia", in Les villes de la Lusitanie Romaine. Hiérarchies et territoires, Paris, 21-34.

Alarcão, J. (1993) “Alfidii e Aufidii de Collippo e Sellium”, Humanitas 45: 193-198.

Alarcão, J. (2004) "As cidades da Lusitânia: imagens de um processo cultural”, in T. Nogales Basarrate (ed.) Augusta Emerita. Territorios, Espacios, Imágenes y Gentes en Lusitania Romana, Mérida, 259-274.

Álvarez Martínez, J. M. e Nogales Basarrate, T. (2003) Forum Coloniae Augustae Emeritae. "Templo de Diana”, Mérida.

Ayerbe Vélez, R.; Barrientos Vera, T. e Palma García, F. (2009 a) "Arquitectura, configuración y restitución de los recintos monumentales", in R. Ayerbe Vélez, T. Barrientos Vera e F. Palma García (eds.) El foro de Augusta Emerita. Génesis y evolución de sus recintos monumentales, Mérida, 667-806.

Ayerbe Vélez, R.; Barrientos Vera, T. e Palma García, F. (2009 b) "Génesis y evolución del foro de Augusta Emerita”, in R. Ayerbe Vélez, T. Barrientos Vera e F. Palma García (eds.) El foro de Augusta Emerita. Génesis y evolución de sus recintos monumentales, Mérida, 807-831.

Bernardes, J. P. (2007) A ocupação romana na região de Leiria, Faro.

Bernardes, J. P. (2010) “Collippo: análise dos espaços públicos”, in T. Nogales Basarrate (ed.) Ciudad y foro en Lusitania Romana, Mérida, 107-120.

Beschi, L. (1986) "La Nike di Hierapytna, opera di Damokrates di Itanos". Rendiconti Linzei, s. 8, 40: 131-143.

Blake, M. E. (1947, rep. Kraus 1968) Ancient Roman construction in Italy, Washington.

Casari, P. (2011) "Iupitter Ammonn e Medusa nella decorazione architettonica forense dell' Adriatico nordorientale", in T. Nogales e I. Rodá (eds.) Roma y las províncias: modelo y diffusion, Roma, vol. 1 93-99.

Correia, V. H. (2013) "Cúria e basílica na evolução do fórum de Conimbriga”. In B. Soler Huertas; P. Mateos Cruz; J. M. Noguera Celdrán e J. Ruiz de Arbulo Bayona, (eds.) Las sedes de los Ordines Decurionum en Hispania. Análisis arquitectónico y modelo tipológico, Mérida, 353-362. 
Encarnação, J. (1984) Inscrições romanas do conventus pacensis, Coimbra.

Gonçalves, L. J. R. (2007) Escultura romana em Portugal: uma arte do quotidiano, Mérida.

Gurval, R. A. (1995) Actium and Augustus: the politics and emotions of civil war, Ann Harbor MI.

Häger-Weigel, E. (1997) Grieschische Akrolith-Statuen des 5 und 4 Jhs. V. Chr., Berlim. Hartswick, K. J. (2004) The gardens of Sallust: a changing landscape, Austin TX.

Huskinson, J. (1975) Roman sculpture from Cyrenaica in the British Museum, Londres.

La Rocca, E. (1985) Amazzonomachia: Le sculture frontonali del tempio di Apollo Sosiano, Roma.

La Rocca, E. (1996) "Athena nella decorazione frontonale del tempio di Apollo sosiano”. Bollettino dei Musei Comunali di Roma N.S. 10: 13-33.

León-Castro Alonso, P. (2011) "Arte romano provincial: Nuevo enfoque y valoración", in T. Nogales e I. Rodá (eds.) Roma y las províncias: modelo y difusión, Roma, vol. 1 23-39.

Lugli, G. (1946) Roma antica. Il centro monumentale, Roma.

Mierse, W. E. (1999) Temples and towns in Roman Iberia, Berkeley CA.

Nogales Basarrate, T. (2007 a) "Culto imperial en Augusta Emerita: imágenes y programas urbanos”, in T. Nogales e J. González (eds.) Culto imperial: política y poder, Roma, 447-540.

Nogales Basarrate, T. (2007 b) "Teatro romano de Augusta Emerita. Evolución y programas decorativos". Mainake 29: 103-138.

Nogales Basarrate, T. (2011) "Plastica romana emeritense en el contexto de Hispania: modelos y difusión”, in T. Nogales e I. Rodá (eds.) Roma y las províncias: modelo y difusión, Roma, vol. 2 653-670.

Nogales Basarrate, T. e Álvarez Martínez, J. M. (2005) "Foros de Augusta Emerita: espácios simbólicos en el urbanismo emeritense", in X. Lafon e G. Sauron (eds.) Théorie et pratique de l'architecture romaine. Études offertes à Pierre Gros, Aix-en-Provence, 213-231.

Nogales Basarrate, T. e Gonçalves, L. J. (2004) “Imagines Lusitaniae: la plástica oficial de Augusta Emerita y su reflejo en algunas ciudades lusitanas". In T. Nogales Basarrate (ed.) Augusta Emerita. Territorios, Espacios, Imágenes y Gentes en Lusitania Romana, Mérida, 285-336.

Nogales Basarrate, T. e Gonçalves, L. J. (2008) "Programas decorativos públicos de Lusitania: Augusta Emerita como paradigma en algunos ejemplos provinciales", in J. M. Noguera Celdrán e E. Conde Guerri (eds.) Escultura Romana en Hispania V, Murcia, 655-696. 
Paribeni, E. (1959) Catalogo delle sculture di Cirene. Statue e rilievi di carattere religioso, Roma.

Peña Jurado, A. (2009) “La decoración escultórica”, in R. Ayerbe Vélez, T. Barrientos Vera e F. Palma García (eds.) El foro de Augusta Emerita. Génesis y evolución de sus recintos monumentales, Mérida, 583-621.

Pensabene, P. (2004) "Roma e le capitali provincial. Contributi per lo studio dell' architettura e della decorazione architettonica in marmo nella Hispania romana", in J. Ruiz de Arbulo (ed.) Simulacra Romae. Roma y las capitales provinciales del occidente europeo, Tarragona, 175-200.

Röring, N. e Trillmich, W. (2010) "Agrippina y la Concordia Augusti. Elementos para la interpretación del 'foro provincial' de la Colonia Augusta Emerita", in T. Nogales Basarrate (ed.) Ciudad y foro en Lusitania Romana, Mérida, 273-284.

Souza, V. (1986) "Escultura Romana", in J. Alarcão (dir.) História da Arte em Portugal - Volume 1 - Do Paleolítico à Arte Visigótica, Lisboa, 129-147.

Souza, V. (1990) Corpus Signorum Imperii Romani Portugal, Coimbra.

Traversari, G. (1973) Sculture del V-IV secolo AC del Museo Archeologico di Venezia, Veneza.

Trillmich, W. (2005) "Monumentalización del espacio público emeritense como reflejo de la evolución histórica colonial: el ejemplo del teatro emeritense y sus fases", in T. Nogales Basarrate (ed.) Augusta Emerita. Territorios, Espacios, Imágenes y Gentes en Lusitania Romana, Mérida, 275-284

Trillmich, W. (2007) "Espacios públicos de culto imperial en Augusta Emerita: entre hipótesis y dudas", in T. Nogales e J. González (eds.) Culto imperial: política y poder, Roma, 415-446.

Zanker, P. (1990) The power of images in the age of Augustus, Ann Harbor MI. 
O modelo iconográfico da Minerva de Collippo e

a sua importância histórica

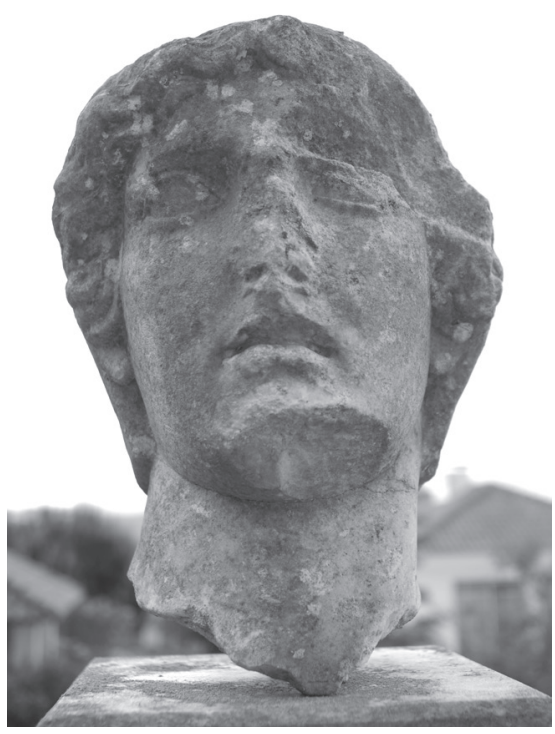

Fig. 1a

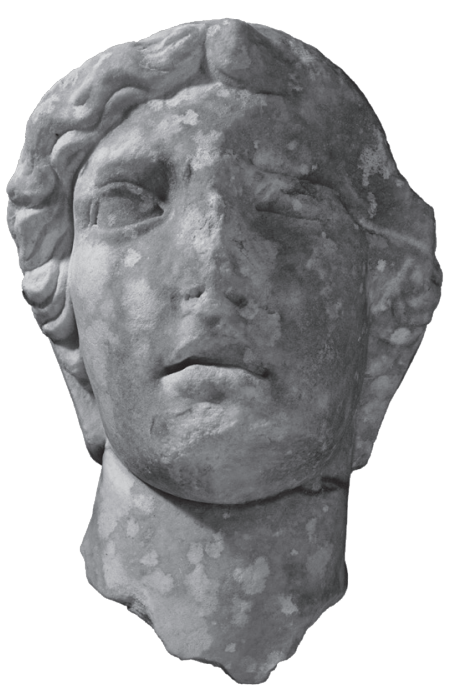

Fig. 2

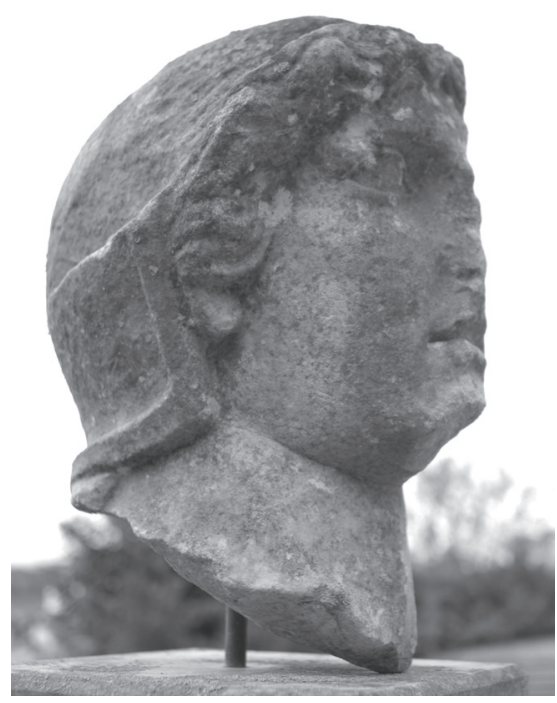

Fig. 1b

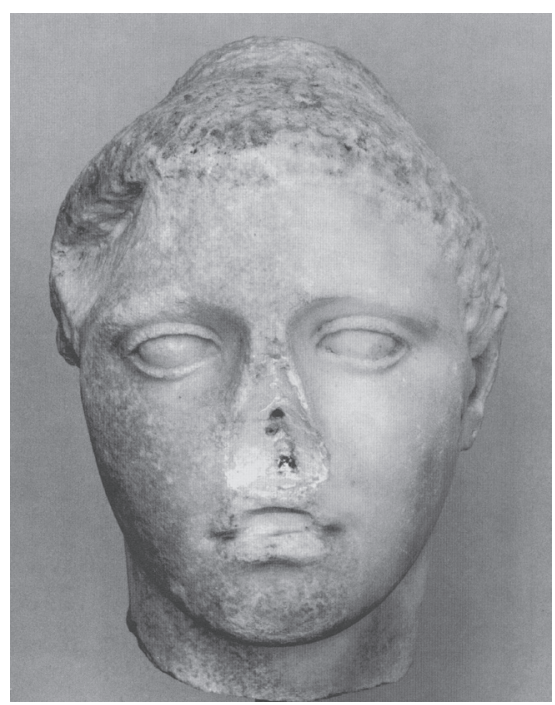

Fig. 3 


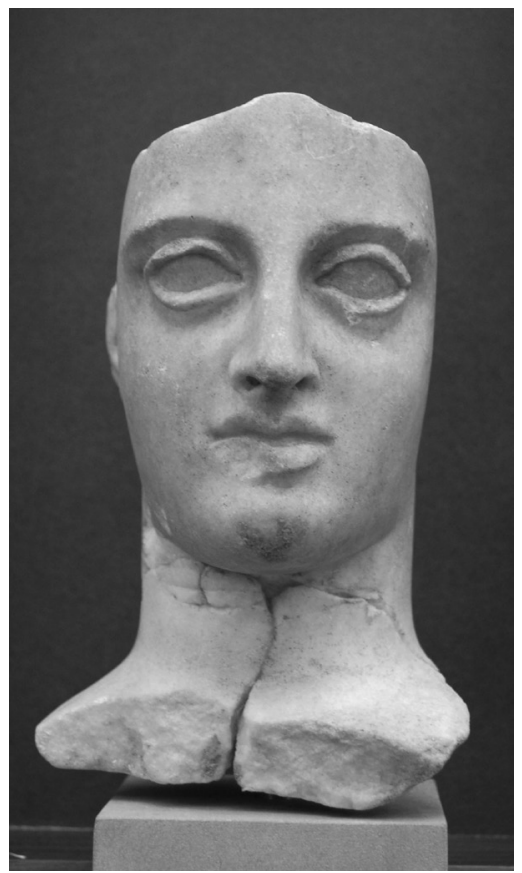

Fig. 4

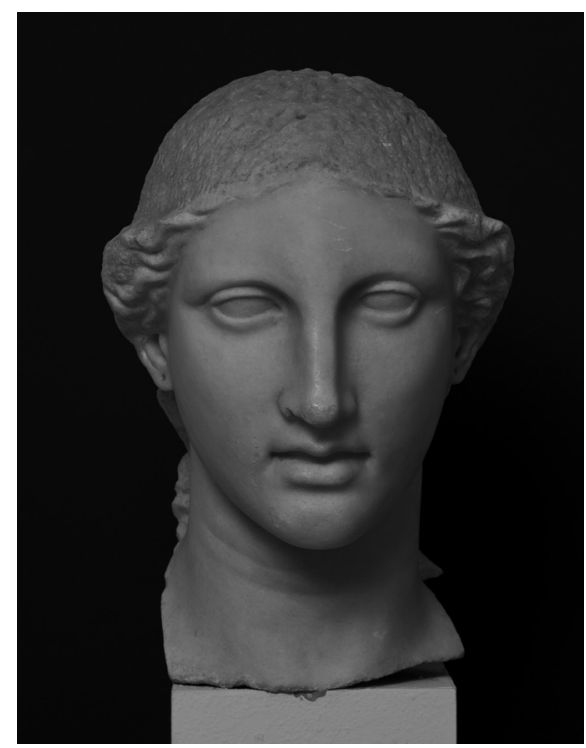

Fig. 5

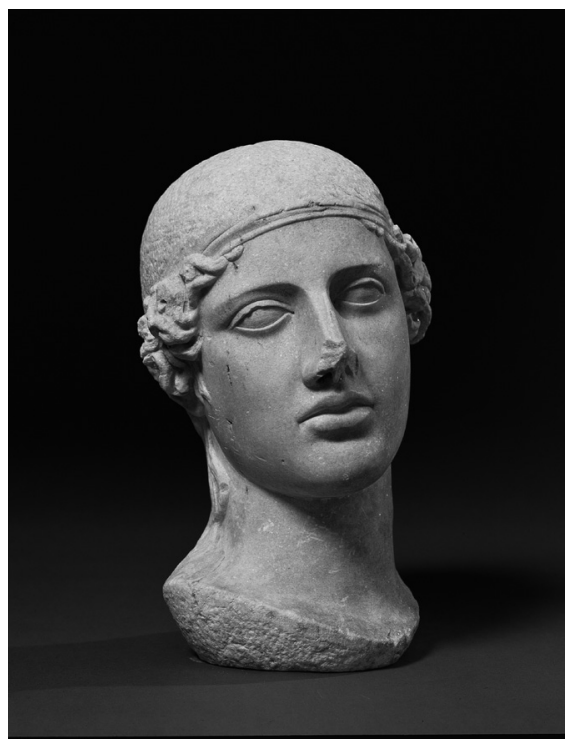

Fig. 6 